\title{
Land for the landless
}

\author{
A. Aguilar \& M. A. Imran \\ College of Arts and Letters, Bicol University, Philippines
}

\begin{abstract}
Typhoons Reming and Milenyo have brought a different challenge to Albayanos. During the last quarter of 2006, two super typhoons hit Albay: Milenyo in September and Reming in November. The latter was the worst that ever hit Legazpi City. The typhoons caused severe damage and devastation to the province. It left thousands of families homeless, destroyed agricultural lands and disrupted people's economic activities. A considerable number of these families are still staying in either designated transit areas and or makeshift houses while those who managed to return to their homes are still struggling with the day-today concerns of restoring their houses and ways of living. Generally, this research was intended to raise awareness, generate sympathy and action among various stakeholders in improving the situations of the families living in tents, makeshifts and even those accommodated by host families through making private or public lands and buildings available for transit use. The research is a 26-minutes video production which showcases the plight of the Albayanos after typhoon Reming; particularly, the internally displaced persons who are still living in tents, evacuation centers, shanties encroaching upon residential areas, and those residing with host families or in unsafe zones. Through the collaborative effort between and among Local Government Units (LGUs) and Non- Government Organizations (NGOs), greater awareness, sympathy and involvement in the lives of the displaced individuals and families have generated both public and private lands and buildings which have been made available for transit use until permanent relocation sites can be provided by the local governments to said victims.

Keywords: landless, internally displaced persons, disaster management, typhoon, mayon eruption, makeshift houses.
\end{abstract}




\section{Introduction}

When typhoons "Milenyo" and "Reming" struck Albay in September and November of 2006, thousands of Bikolanos from all walks of life experienced displacements of all sorts. The effects of the typhoon aggravated by mass hysteria and disorientation, traumatized and weakened the resiliency of the people. Many saw the death of their loved ones, destruction of their homes and properties some huddled in schools, makeshift houses, and even in tents which served as their evacuation centers. Those who opted to return to their ruined homes had to contend with the incessant rains, lack of electric power supply as well as the scarcity of food and drinking water.

The towns of Daraga, Camalig, Guinobatan and Legazpi City suffered from tons of volcanic debris that cascaded down the slopes of Mayon Volcano at the height of typhoon "Reming" meeting with the rampaging current from swollen rivers as the wind and rain lashed at the gloomy landscape. This deluge was recorded by various media from radio, newspaper to television channels both local and foreign affirming through harrowing images of corpses washed away by the flood or crushed by rumbling boulders; bodies and belongings tossed out of homes by the tempestuous wind or pinned to the ground by the rubble (Global Medic [1]).

As of December 29, 2006, there were 18,158 individuals housed in 57 different evacuation centers in Albay province. The three heavily damaged areas typhoon Reming were in the Municipalities of Daraga, Guinobatan and the City of Legazpi. In fact, $44 \%$ or the most number of evacuees were from Daraga, $21 \%$ Legazpi, and $18 \%$ from Guinobatan. A considerable number of these families were still staying either in designated transit areas, or evacuation centers while those who managed to return to their homes were still struggling with their needs and concerns of restoring their ruined houses and the normalcy of their everyday living. The impact of the disaster was widespread and devastating. It left so much physical destruction and losses not to mention emotional trauma among residents of the affected areas due to numerous deaths, damaged government and private facilities, agricultural lands and produce including ecological disturbances that lead to incalculable socio-economic deprivation.

This was the aftermath of the typhoon to many of the Albayanos, who had to live in uncomfortable temporary shelters provided for by the government, nongovernment organizations in badly hit areas. They tried to cope with the difficult life by adapting to a new environment, while at the same time worrying about their next meal and where their daily needs would come from. The typhoon also brought a dilemma to the Local Government Units. Finding solutions to the problems was an immediate task; however, their capacity to respond quickly to the needs of the typhoon victims was very limited. Fortunately, external organizations extended assistance and filled in these gaps in several places in the province. One of which was the major intervention made by the International Organization for Migration (IOM) a non-government organization involved in the provision of cash grants for land development for the landless; ensure the orderly and humane management of migration, assist in search for practical 
solutions to migration problems and provide humanitarian assistance to migrants in need. The IOM Project is an initiative to raise awareness and generate sympathy and action among the stakeholders in improving the situation of the families living in tents, makeshift houses and in hosted families through making private and public lands and buildings available for transit use. The project was initiated in several towns of the province in January 2007 until 2008.It is a detailed and well formulated strategy that aimed to be more than just a mere grant of land. It was a committed effort to address poverty from all angles including agricultural, economic, social, and financial assistance. In order to mitigate internally displaced person's sufferings and improve their standard of living is to come up with a strong collaborative strategy to transform their present condition and accept their status within their social culture. The challenge now lies on how to convince the landowners and the government to grant the land for the landless, even for a time, hence a video production was made showing the plight of the Albayanos after the devastating typhoon Reming.

\section{Review of related literature}

In the whole of Asia, the Philippines ranked fourth as the top most disaster prone country. This is one of the reasons why more than $75 \%$ of their population, especially in rural areas lives below the poverty line. Over the last ten years, Citizens Disaster Response Center has observed an increasing number of disaster events and a growing number of persons were affected by disasters. At the start of the new millennium, from an average of 7 million affected by both natural and human induced-disasters in the 1990s, and the average population affected by disasters rose to 9 million by 2001.In the Philippines, Filipinos withstand the wrath of at least 20 typhoons; grieved over deaths and ruins of fires that raze an average of 7,300 houses; sympathized with the hundreds of thousands of internally displaced brothers and sisters not only in Mindanao, but also in many other parts of the country. Major disasters like the 1990 killer earthquake in Luzon, the Mt. Pinatubo eruption, in the recent 2003 landslides in Southern Leyte, 2004 landslides in Aurora provinces, the February 2006 rockslides in St. Bernard and the landslides in many parts of the Bicol Region, put many families and communities in disarray (Tablang [2]). Natural disasters have been considered man's greatest enemy. It is an extreme sudden event caused by environmental factors that injure people and damage properties. Earthquakes, typhoons, floods, tsunamis, volcanic eruptions, landslides, and diseases all strike anywhere without man's forewarning and it happens when man is unprepared. The disaster may strike suddenly, yet its effect will be felt for quite a long time. Man and government are in the same mind trying to control or minimize the cost of damages, if not fully eradicated (Aguilar [3]).

The United Nations has taken significant steps to respond to the needs of Internally Displaced Persons (IDPs). The internally displaced persons are those who have been forced or obliged to flee or leave their homes as a result in order to avoid the effects of armed conflicts, gross violation of human rights or natural or human-made disasters but who remain within the borders of their own 
countries. Disasters, natural or man-made events wherein communities experience severe danger and incur loss of lives and properties causing disruption in its social structure and prevention of the fulfillment of all or some of the affected community's essential functions. The guiding principles on internally displaced persons like the victims of typhoons Milenyo and Reming include the right to adequate standard of living. At the minimum, regardless of circumstances, and without discrimination, authorities shall provide essential food, potable water, basic shelter, housing, clothing, medical services and sanitation. Education and livelihood training facilities shall be made available to victims whether or not living in camps. The framework intends to contribute to pro-people development and improve the quality of lives of Filipinos. Hinging on community development, it maintains that people-oriented development is the goal and process of reducing vulnerabilities and increasing the capacities of the marginalized sectors. It is citizenry-based because it banks on the capability of Filipinos to respond to their situations. On the other hand, it is developmentoriented because it tends to address the root causes of vulnerability through an empowerment process.

Through the past exposure of Bicolanos to disasters and other experiences, they have intentionally or unintentionally developed coping mechanisms and other strategies to deal with disasters. CBDO-DR suggests that capacities such as these are strengthened (Heijmans and Victoria [4, p. 28]) but the framework goes beyond strengthening capacities. It also suggests that as hazards may not be prevented, the negative effects would be lessened by tackling peoples' vulnerabilities and their root causes (Heijmans and Victoria [4, p. 37]). For example, if people have problems working with one another, there may be a need to address the power relations within their organization or community. Also, it suggests that actual participation in disaster response activities allows people to address their other needs. By addressing their disaster-related concerns, they develop resource control and power relations, among others, and, in the process, become more empowered (Heijmans and Victoria [4, p. 39]). On the other hand, community-based approach to disaster management is also vital to poverty alleviation as it keeps people and assets from disaster risks preventing disruptions on poverty reduction and other development efforts (Torrente et al. [5]).

Finally, it emphasizes the importance of organizational and social support networks during crises and emergency situations. An example is the grassroots disaster response organizations (GDROs) which enable communities and groups to work take part in pre, during, and post-disaster scenarios. These GDROs are essential in mobilizing communities and expanding membership and linkages with the less vulnerable groups in a community (Campañano-Bernardo and Geronimo [6]). 


\section{Methodologies}

\subsection{Document review}

The research team interviewed the IDPs, community organizers, Barangay Captains regarding their plights and sentiments. At the LGU level, the ordinances and resolutions which served as indicators of programs and plans of the government were also included. Moreover, the research team tried to gather documents from the community, internet, published books and reports that could be the basis of programs for development.

\subsection{Key informant interviews}

The executive director of IOM was the chosen key informant. At the LGU level, the Mayor or his/her representative, Sanggunian Secretariat was interviewed about their initiatives to respond to the concerns of IDPs in relation to Reming damages. IDPs were engaged into short informal interviews/conversations to generate information about the challenges of their plight during Reming.

\subsection{Ethnovideography}

The audio visual data on the Reming aftermath was used in this study.

\section{Significant findings}

1. As of December 29, 2006, there were 18,158 individuals housed in 57 different evacuation centers in Albay province. The three heaviest areas damaged the typhoon Reming were in the Municipalities of Daraga, Guinobatan and the City of Legazpi. In fact, $44 \%$ or the most number of evacuees were from Daraga, $21 \%$ Legazpi, and 18\% from Guinobatan. A considerable number of these families were still staying either in designated transit areas, or evacuation centers while those who managed to return to their homes were still struggling with their immediate concerns of restoring their houses and the normalcy of everyday living.

2. Various organizations and private individuals helped the IDPs in rebuilding their homes; and after debriefings conducted by well-meaning sectors most of them have moved a little further away from the pain and trauma caused by the nightmare, and are now focused on their day-to-day existence.

3 . The assistance required for the internally displaced persons would include (1) housing; (2) health care and medical attention; (3) livelihood and financial assistance and (4) psychosocial counseling. The affected communities requested for the above mentioned priorities citing the fact that they were in dire need of food, clothing and shelter, medicine and money. Psychosocial counseling visits and frequent conversations with the typhoon victims helped in the release of their anxieties and tensions. 
4. The collaborative effort of various LGUs and NGOs was laudable as it produced positive results. It is hoped that such positive effects will prove to be long-lasting and that the socio-economic programs of the internally displaced families will be sustainable. To alleviate internally displaced persons' sufferings and improve their standard of living is to come up with a strong collaborative strategy to transform their present condition and allow them to accept the new role within their social culture.

\section{Conclusions}

1. The video documentary produced by this research is a testament to the large scale devastation, displacement and wanton destruction brought about by Typhoon Reming; the strongest so far in the history of Albay Province.

2. Unstructured interviews conducted among victims and survivors of the unsurpassed calamity in the City of Legazpi, and the municipalities of Sto. Domingo, Daraga, Camalig and Guinobatan; show their acceptance that life goes on despite the pain, suffering and confusion brought about by the catastrophe. They have started picking up the pieces of their broken lives and galvanized by their will to survive, are now focused on their day-to-day living.

3. Both the video documentary and interviews show that the once populated and busy habitats of Padang, Maipon, etc., have been transformed into a "no man's land"; and that previous residents have migrated to other safer places with the hope of starting life anew.

4. Through the collaborative efforts among and between LGUs and NGOs, greater awareness, sympathy and involvement in the lives of the displaced individuals and families have generated public and private lands and buildings which have been made available for transit use until permanent relocation sites can be provided by the local governments for said victims.

\section{Recommendations}

1. The budget is always the basic ingredient for any development program. LGU officials more often than not seem supportive of development initiative, but lack the political will to earmark specific financial support for a program. Legislation is necessary in order to institutionalize said programs.

2. There is a need for a policy collaboration between and among the public and private partnerships and create coordinating councils that would help in the relocation, mitigation and adaptation of the IDPs.

3. To ensure effectiveness, linkages with the academe, NGOs and communitybased development organizations should be fostered. There should be a policy enforced to institutionalize initiatives within the LGU for a wider participation among the stakeholders.

4. The vulnerabilities of the IDPs should be addressed first at the personal level and at the same time their capacities should be further enhanced in order to overcome the external difficulties and achieve a resilient community. To mitigate internally displaced persons' sufferings and improve their standard of living is to 
come up with a strong collaborative strategy to transform their present condition and accept their new role within the social culture.

5. Further studies can be made to asses into the IDPs conditions after temporary or permanent houses have been built.

\section{References}

[1] http://www.globalmedic.ca/ retrieve from the net.

[2] Tablang R.C. Building Disaster-resilient Communities and Creating a Culture of Disaster Preparedness: The Community-based Disaster.2007

[3] Aguilar, E. Philippine Daily Inquirer, 2006.

[4] Heijmans, A. and Victoria, LP. Citizenry-Based \& Development-Oriented Disaster Response: Experiences and Practices in Disaster Management of the Citizens' Disaster Response Network in the Philippines. Philippines: Center for Disaster Preparedness, 2001.

[5] Torrente E., Zhang J., Le-Huu T., CBDRM and Poverty Reduction, Asian Disaster Preparedness Center, United Nations, 2008.

[6] Campañano-Bernardo D.M and Geronimo J. A Looking at 'Ondoy' Experience as a Constructive Phenomenon: An Initial Situational Analysis in Mainstreaming Older Person's Development Perspectives in a Community-Based Disaster Risk Management Program, University of the Philippines, 2010. 